\title{
The potential impact of including pre-school aged children in the praziquantel mass-drug administration programmes on the S.haematobium infections in

\author{
Malawi: a modelling study
}

\author{
Iwona Hawryluk ${ }^{1 *}$, Tara Mangal ${ }^{1}$, Andrew Nguluwe ${ }^{2}$, Chikonzero Kambalame ${ }^{2}$, Stanley Banda ${ }^{2}$, \\ Memory Magaleta², Lazarus Juziwelo ${ }^{2}$, Timothy B. Hallett ${ }^{1}$ \\ ${ }^{1}$ MRC Centre for Global Infectious Disease Analysis; and the Abdul Latif Jameel Institute for Disease and \\ Emergency Analytics (J-IDEA), School of Public Health, Imperial College London, London, UK \\ ${ }^{2}$ Community Health Science Unit, Department of Schistosomiasis \& Soil-Transmitted Helminths, Ministry of \\ Health, Lilongwe, Malawi
}

\begin{abstract}
Background: Mass drug administration (MDA) of praziquantel is an intervention used in the treatment and prevention of schistosomiasis. In Malawi, MDA happens annually across high-risk districts and covers around $80 \%$ of school aged children and $50 \%$ of adults. The current formulation of praziquantel is not approved for use in the preventive chemotherapy for children under 5 years old, known as preschool aged children (PSAC). However, a new formulation for PSAC will be available by 2022. A comprehensive analysis of the potential additional benefits of including PSAC in the MDA will be critical to guide policy-makers.
\end{abstract}

Methods: We developed a new individual-based stochastic transmission model of Schistosoma haematobium for the 6 highest prevalence districts of Malawi. The model was used to evaluate the benefits of including PSAC in the MDA campaigns, with respect to the prevalence of high-intensity infections (> 500 eggs per $\mathrm{ml}$ of urine) and reaching the elimination target, meaning the prevalence of high-intensity infections under $5 \%$ in all sentinel sites. The impact of different MDA frequencies and coverages is quantified by prevalence of high-intensity infection and number of rounds needed to decrease that prevalence below $1 \%$.

Results: Including PSAC in the MDA campaigns can reduce the time needed to achieve the elimination target for $S$. haematobium infections in Malawi by one year. The modelling suggests that in the case of a lower threshold of high-intensity infection, currently set by WHO to 500 eggs per $\mathrm{ml}$ of urine, including PSAC in the preventive chemotherapy programmes for 5 years can reduce the number of the highintensity infection case years for pre-school aged children by up to 9.1 years per 100 children.

Conclusions: Regularly treating PSAC in the MDA is likely to lead to overall better health of children as well as a decrease in the severe morbidities caused by persistent schistosomiasis infections and bring forward the date of elimination. Moreover, mass administration of praziquantel to PSAC will decrease the prevalence among the SAC, who are at the most risk of infection.

Keywords: schistosomiasis, Malawi, praziquantel, mass drug administration, mathematical modelling 
medRxiv preprint doi: https://doi.org/10.1101/2020.12.09.20246652; this version posted December 11,2020 . The copyright holder for this preprint (which was not certified by peer review) is the author/funder, who has granted medRxiv a license to display the preprint in It is made available under a CC-BY-NC-ND 4.0 International license .

\section{Background}

Schistosomiasis is one of the Neglected Tropical Diseases, caused by parasitic worms of the genus Schistosoma. All types of schistosome flukes have similar life cycles, requiring freshwater environment and intermediate snail hosts $(1,2)$. People get infected by contact with water containing free-living cercariae. It is estimated that over 230 million people worldwide are at risk of the schistosomiasis infection, contributing to around 100,000 Years Lived with Disability annually (3). Studies have shown that around $90 \%$ of all schistosomiasis cases happen in Africa, with sub-Saharan Africa experiencing the highest burden (4).

For the urogenital infections, caused by $S$. haematobium, the most common symptoms are haematuria (blood in urine) and dysuria (painful urination). Prolonged infections lead to a number of complications, including bladder wall pathologies, hydronephrosis and renal dysfunctions, which can progress into bladder cancer or severe kidney failure. The infections may cause infertility in women and increase the risk of acquisition of HIV and HPV viruses (5-7).

As the burden of schistosomiasis is the highest among the school aged children (SAC; 5-15 years old), the burden among the pre-school aged children (PSAC; $<5$ years old) is often overlooked (8). Although it is hypothesised that morbidity relates to the worm burden and that light infections, defined as having under 500 eggs per $\mathrm{ml}$ of urine, are likely to be asymptomatic in adults, there is little evidence of how the worm burden relates to morbidity in PSAC (9). A few studies have hypothesised that the severe and irreversible complications in adulthood are a consequence of a chronic worm burden during childhood (9). Moreover, schistosomiasis infections, even of relatively low intensity, can cause anaemia, malnutrition and stunted intellectual and physical growth.

Despite the burden of infection in PSAC, they are not included in the mass drug administration (MDA) campaigns as the current formulation of praziquantel has not been approved for use in large-scale preventive chemotherapy of children under 5 years old $(10,11)$. However, a new paediatric praziquantel is currently in clinical trials and is anticipated to be licensed for use by 2022 (12). The release of the paediatric praziquantel raises a question on the potential implications of including PSAC in the MDA campaigns. Mathematical modelling is typically used in such situations to simulate the possible outcomes in various treatment scenarios. For schistosomiasis, such approaches have been used, for example, to advise on the MDA requirements for eliminating the infection worldwide (13), to predict the impact of introducing vaccinations against S.mansoni infections (14), or to evaluate the cost-effectiveness of the community-wide mass treatment (9).

According to a recent study, which analysed data on schistosomiasis infections in 11 countries, the substantial effort devoted to eliminating schistosomiasis in Malawi resulted in reaching the 'elimination as a public health problem' WHO target for the S.mansoni infections (prevalence of high-intensity infections $<1 \%$ in all sentinel sites) and the morbidity control target for S.haematobium (prevalence of high-intensity infections $<5 \%$ ) (15). Although schistosomiasis infections affect mostly children, about $80 \%$ of employment in Malawi is in the agricultural sector, and therefore a large fraction of the adult population is still at risk of being exposed to the infested water reservoirs (16).

In this study, we analyse the potential impact of including PSAC in the mass drug administration programmes in Malawi by looking at the potential to reach the WHO elimination target in SAC and the change in the prevalence of the high intensity infections in PSAC with MDA coverage and frequency. We build upon an existing multi-disease model framework which simulates lifetime health and health system interactions of the Malawian population. Our focus is on the 6 districts with the highest prevalence of S.haematobium infections.

\section{Methods}

\section{Transmission model}

The transmission model developed in this project has an individual-based stochastic structure. Each individual has an underlying propensity to become infected, termed the 'harbouring rate', drawn from a gamma distribution with scale parameter $=1$. The harbouring rate is set this way in order to match the data on the clustering of the 
medRxiv preprint doi: https://doi.org/10.1101/2020.12.09.20246652; this version posted December 11,2020 . The copyright holder for this preprint (which was not certified by peer review) is the author/funder, who has granted medRxiv a license to display the preprint in

It is made available under a CC-BY-NC-ND 4.0 International license .

worm burden in certain individuals. The shape parameter $k_{\text {district }}$ of the gamma distribution is calibrated to every district and independent of any other individual properties, such as age or place of residence within the district, as described in more detail further in this manuscript. The contribution to the infectious material reservoir and the frequency of infectious contacts with the water is governed by the age-dependent exposure rate $\beta_{\text {age. }}$.

At each time step (1 month), the size of the infectious reservoir is calculated by summing up each individuals' contributions, that is their current worm burden (WB) multiplied by the exposure rate. The full lifecycle of the schistosomes is simplified and subsumed into the district-dependent parameter $R_{0}$, defined here as the average number of female offspring produced by a female worm that effectively infects the definitive human host and survives to maturate into adults. New worms are acquired according to the Poisson distribution, with a rate dependent on the exposure and harbouring rates and the size of the reservoir in the district. The overall distribution of the worm burden in the population, arising from mixing the Poisson and gamma distribution this way is negative binomial, which agrees with the data from the autopsy studies (17). The worms mature to adulthood within 25-30 days and die naturally after 6 years unless they are killed by praziquantel during the mass drug administration before that.

Births and deaths due to any cause are informed by data from United Nations fertility and mortality estimates (18) and Malawi Population and House Census from 2018 (19). We assume no increase in the death rate with schistosomiasis infection, and no immunity gained due to repeated infections. The outputs have a full age structure, but for the presentation of the results, they have been grouped into the 3 age groups: PSAC (0 to 4 years old), SAC (5 to 14 years old) and Adults (15 to 100 years old).

Additional details of the transmission model are available in the Supplementary Information. All parameters used in the transmission model are given in Table 1 and Table 3.

Table 1 Parameters for the S. haematobium transmission model.

\begin{tabular}{|c|c|c|c|}
\hline Parameter & Parameter description & Value & Reference \\
\hline $\mathrm{k}$ & $\begin{array}{l}\text { Shape parameter of the gamma } \\
\text { distribution, used to assign the } \\
\text { harbouring rates }\end{array}$ & \multirow{2}{*}{$\begin{array}{l}\text { Depending on the } \\
\text { district }\end{array}$} & \multirow{2}{*}{$\begin{array}{l}\text { Calibrated, see } \\
\text { Table } 3\end{array}$} \\
\hline $\mathrm{R}_{0}$ & $\begin{array}{l}\text { average number of female offspring } \\
\text { produced by a female worm }\end{array}$ & & \\
\hline$\beta$ PSAC & \multirow[t]{3}{*}{ Age-dependent exposure rate } & 0.3 & \multirow{3}{*}{ (20) } \\
\hline$\beta_{S A C}$ & & 1 & \\
\hline$\beta_{\text {Adults }}$ & & 0.05 & \\
\hline $\begin{array}{l}\text { Maturation } \\
\text { period }\end{array}$ & $\begin{array}{l}\text { Time from infecting an individual to } \\
\text { reach adulthood }\end{array}$ & $25-30$ [days] & (21) \\
\hline Worm lifespan & Adult worm life expectancy & 6 [years] & (22) \\
\hline
\end{tabular}

\section{Calibrating parameters}

Parameters $k$ and $R_{0}$ were calibrated to the given prevalence of every district following the methodology from previous studies $(22,23)$. For the calibration, we used the baseline prevalence data obtained from the ESPEN database (24) and filtered for Malawi, years 2002-2012, that is prior to the MDA campaigns being rolled out in the country. We assumed a linear relationship between the parameter $k$ and the baseline prevalence, as reported previously for soil-transmitted helminths (STH) (23), with the slope coefficient fitted using a grid search method. The details of the calibration are provided in the Supplementary Information. Where data for multiple locations within one district were found, an unweighted mean was used in the model as prevalence. The questions we set to answer consider only the six districts with the highest prevalence according to the most recent data available: Blantyre, Chiradzulu, Mulanje, Nkhotakota, Nsanje and Phalombe. 
medRxiv preprint doi: https://doi.org/10.1101/2020.12.09.20246652; this version posted December 11,2020 . The copyright holder for this preprint (which was not certified by peer review) is the author/funder, who has granted medRxiv a license to display the preprint in

It is made available under a CC-BY-NC-ND 4.0 International license .

High-intensity infections

Clinically, a high-intensity infection is recognised as one in which the individual has a measurable number of eggs per $\mathrm{ml}$ of urine (epml) that exceeds a certain threshold. The WHO proposes a threshold of $500 \mathrm{epml}$ for S.haematobium infections (10). Our model tracks the number of worms carried by each individual, not the number of eggs excreted. However, we assume that the number of eggs excreted will be related linearly to the WB and that male and female worms have the same characteristics in all respects, such that we can relate the threshold epml, to a threshold WB, as:

$$
\operatorname{High}_{W B}=\frac{\text { WHO threshold }}{\text { Eggs per worm pair }} * 2
$$

We assume that each worm pair causes a net output of $52 \mathrm{epml}(20)$. Applying the above equation, the highintensity infection threshold for urogenital infections is equivalent to a WB of 20 worms in our model.

\section{Mass drug administration}

In our model, the individuals selected for treatment are sampled randomly from each age group according to the reported coverage. We assume $100 \%$ efficacy of praziquantel in killing adult worms a $100 \%$ systematic compliance.

For years 2015 - 2018 the data regarding the coverage of MDA programmes in every district of Malawi, collected and shared by The Department of Schistosomiasis and Soil-Transmitted Helminths (Malawi Ministry of Health, Community Health Science Unit) were used in the model (data is available in the Supporting Information). The data consist of the coverage of the school-based programmes and community treatment. PSAC were not included in the programme, as per the WHO guidelines (10)After 2019, the coverage and frequency of MDA are varied. The details of the MDA events executed in the simulations are listed in Table 2.

Table 2 MDA events details. The compliance and efficacy was assumed to be $100 \%$ in all scenarios analysed.

\begin{tabular}{|l|l|l|l|}
\hline MDA events & Reference & $\begin{array}{l}\text { Treatment } \\
\text { frequency }\end{array}$ & $\begin{array}{l}\text { PSAC } \\
\text { coverage }\end{array}$ \\
\hline $\begin{array}{l}\text { MDA in each district in } \\
\begin{array}{l}2015-2018 \text { (SAC and } \\
\text { Adults) }\end{array}\end{array}$ & $\begin{array}{l}\text { MDA Malawi data; for 2016 the coverage data } \\
\text { were interpolated from years 2015, 2017, 2018 } \\
\text { Coverage per age group and district is given in } \\
\text { the Supplementary Information. }\end{array}$ & Annual & $0 \%$ \\
\hline $\begin{array}{l}\text { MDA in each district in } \\
\text { years following 2018 }\end{array}$ & Simulated scenarios & Annual & $\begin{array}{l}0 \%, 25 \%, \\
50 \%\end{array}$ \\
\cline { 2 - 4 } & & Biannual & $0 \%, 50 \%$ \\
\hline
\end{tabular}

\section{Summary of the analysis}

The analysis was split into three parts. Firstly, the simulations were run for 25 years simulation time in order to achieve equilibrium and validate the model by comparing the estimated prevalence with the baseline ESPEN data (24). Secondly, to explore the possible timelines of reaching the WHO elimination target, we looked at the prevalence of the high-intensity infections among SAC in each of the MDA scenarios, as specified in Table 2. We then extracted the number of MDA rounds required to decrease the prevalence of high-intensity infections under $1 \%$. Finally, to investigate the impact of the MDA on the high-intensity infections in children, we performed a sensitivity analysis, in which we re-run the simulations with varied WB threshold, above which the infection can be defined as high-intensity infection. The outcomes were quantified by looking at the change in the prevalence of high-intensity infections among PSAC, number of rounds needed to bring that prevalence below $1 \%$, and calculating high-intensity infection years averted in each MDA scenario.

In all simulations, the population size was 10,000 people, split across the 6 districts under analysis (Blantyre, Chiradzulu, Mulanje, Nkhotakota, Nsanje and Phalombe) weighted by the population size and preserving the demographic profile of each district. The results are combined for all 6 districts under analysis. For every MDA 
medRxiv preprint doi: https://doi.org/10.1101/2020.12.09.20246652; this version posted December 11,2020 . The copyright holder for this preprint (which was not certified by peer review) is the author/funder, who has granted medRxiv a license to display the preprint in

It is made available under a CC-BY-NC-ND 4.0 International license .

scenario, we ran 3 simulations with the same coverage and frequency, as specified in Table 2, and focus on the average outcome.

\section{Results}

Model validation

The distribution of the worm burden in the population after 25 years of simulation time is shown in Figure 1. The worm burden is negative-binomially distributed, agreeing with autopsy studies (17), with the peak of the mean worm burden (MWB) observed for the SAC (5-15 years old), as expected. The differences between the age groups are much higher in the MWB than prevalence, which is consistent with the previous findings (22). The prevalence in each of the 6 districts produced by the model presents a good fit to the data (Table 4).
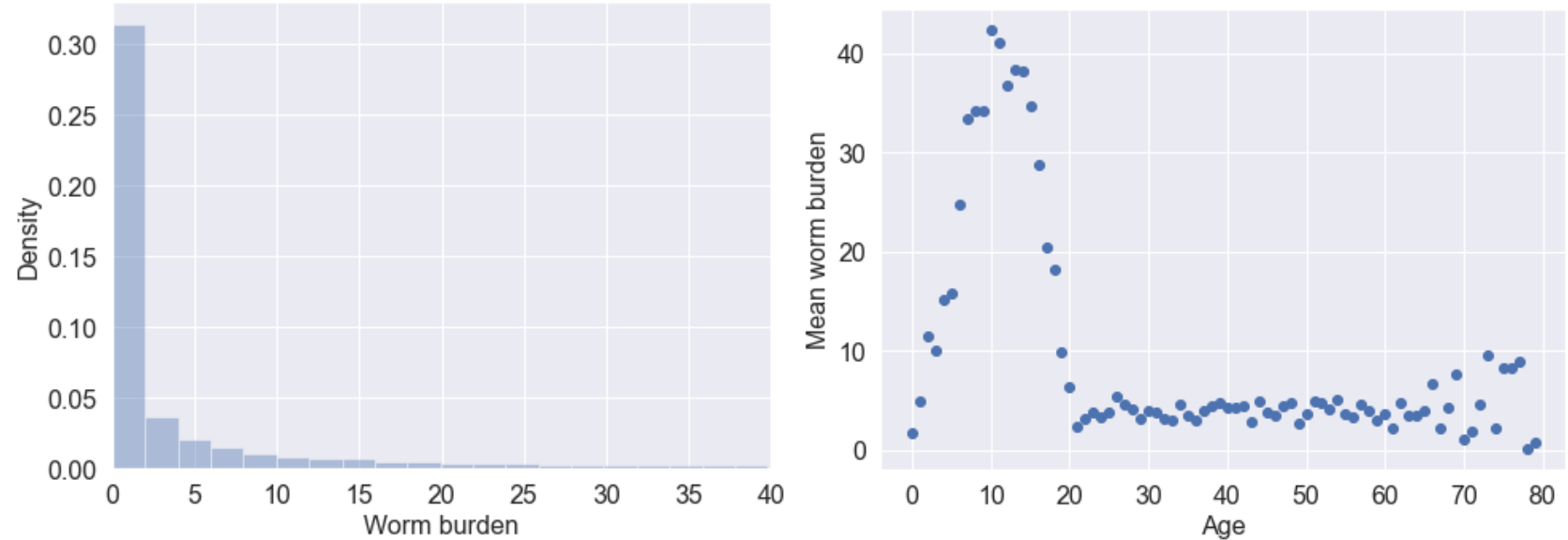

Figure 1 Worm burden generated by the model after running simulations for 25 simulation-years. (Left) Distribution of the worm burden in the total population. The fitted negative binomial distribution has a clumping parameter $k=0.125$ and mean = 13.443 (fitting performed with $R$ statistical software); the clumping parameter is comparable with the $k$-value from other studies (20,22). (Right) Age profile of the mean worm burdens in the entire simulated population.

Table 3 Average prevalence and mean worm burden per district after running 12 simulation for 25 years, without MDA, standard deviation given in brackets. Baseline prevalence was obtained from (24). Parameters $k$ and $R_{0}$ were calibrated to the baseline prevalence as described in the Methods. The last three columns show the outputs of the model: prevalence, mean worm burden and prevalence of high-intensity infections.

\begin{tabular}{|l|l|l|l|l|l|l|}
\hline District & $\begin{array}{l}\text { Baseline } \\
\text { prevalence (\%) }\end{array}$ & $\mathrm{k}$ & $\mathrm{R}$ & $\begin{array}{l}\text { Model prevalence } \\
(\%)(\mathrm{sd})\end{array}$ & $\begin{array}{l}\text { Model mean worm } \\
\text { burden }(\mathrm{sd})\end{array}$ & $\begin{array}{l}\text { Model high-intensity infection } \\
\text { Prevalence }(\%)(\mathrm{sd})\end{array}$ \\
\hline Blantyre & 26.9 & 0.108 & 1.130 & $23.6(1.27)$ & $5.25(0.73)$ & $7.1(0.98)$ \\
\hline Chiradzulu & 34.4 & 0.138 & 1.141 & $36.1(1.38)$ & $11.94(1.44)$ & $14.2(1.47)$ \\
\hline Mulanje & 36.0 & 0.144 & 1.145 & $39.1(0.78)$ & $14.13(1.17)$ & $16.5(1.58)$ \\
\hline Nkhotakota & 29.8 & 0.119 & 1.133 & $28.2(1.30)$ & $7.27(0.85)$ & $9.5(1.16)$ \\
\hline Nsanje & 31.3 & 0.125 & 1.136 & $31.9(1.64)$ & $9.70(1.62)$ & $11.8(1.70)$ \\
\hline Phalombe & 47.0 & 0.188 & 1.184 & $53.2(0.87)$ & $27.45(1.60)$ & $27.7(1.07)$ \\
\hline
\end{tabular}

The effect of including PSAC in MDA on reaching the elimination target

To examine whether including PSAC in the mass treatment can accelerate reaching the WHO elimination goal, we looked at the predicted prevalence of high-intensity infections in SAC (Figure 2) and the number of treatment rounds needed to achieve the prevalence of high-intensity infections less than $1 \%$, shown in Table 4 . If the treatment happens annually, including PSAC with the coverage of just $25 \%$ caused the SAC to reach the elimination target within the first 2 additional treatment rounds, as opposed to 3 when PSAC were not included. 
medRxiv preprint doi: https://doi.org/10.1101/2020.12.09.20246652; this version posted December 11,2020 . The copyright holder for this preprint (which was not certified by peer review) is the author/funder, who has granted medRxiv a license to display the preprint in It is made available under a CC-BY-NC-ND 4.0 International license .
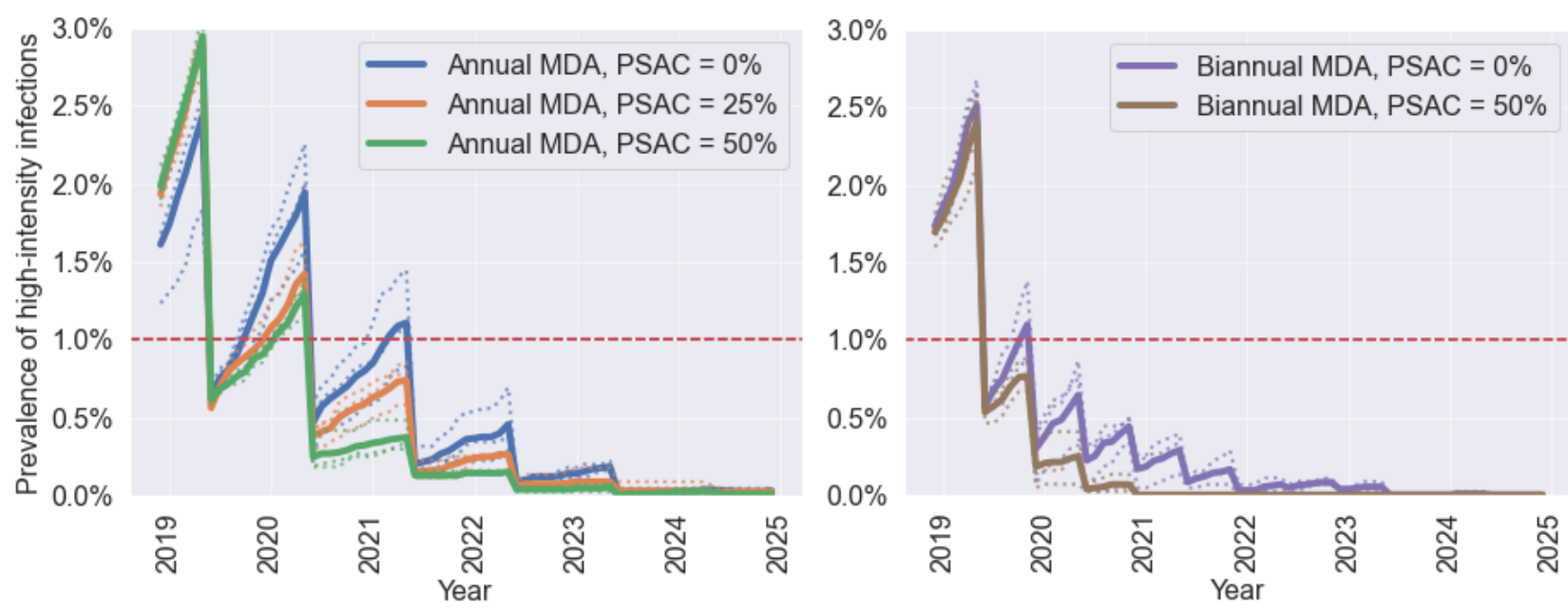

Figure 2 Prevalence of high-intensity infections (over 500 epml, corresponding to around 20+ worms) in SAC depending on the MDA strategy. In all simulations, SAC coverage was fixed to $80 \%$ and Adults coverage to $50 \%$. The PSAC coverage was varied between $0 \%$ and $50 \%$, as indicated by the plot's legends. Plot on the left shows simulated outcomes for the annual MDA, and the plot on the right for the biannual MDA. The red line denotes the $1 \%$ high-intensity infections prevalence, that is the elimination as a public health problem target defined by the WHO.

Table 4 Number of treatment rounds needed to reach the $1 \%$ prevalence of high-intensity infections elimination target for SAC in simulations with annual and biannual MDA.

\begin{tabular}{|l|l|l|}
\hline PSAC coverage & Annual MDA & Biannual MDA \\
\hline $0 \%$ & 3 & $2(1$ year $)$ \\
\hline $25 \%$ & 2 & Not analysed \\
\hline $50 \%$ & 2 & $1(0.5$ year $)$ \\
\hline
\end{tabular}

High-intensity infections in PSAC

Based on these results, in Table 5 we show the expected number of MDA rounds required to decrease the prevalence of high-intensity infections below $1 \%$. If the current strategy of MDA continues, our model predicts that 5 more rounds will be required to reach $1 \%$ prevalence of high-intensity infections among PSAC with the threshold of 5 worms, compared to 2 years if the threshold is the same as for SAC, that is 20 worms. By including the PSAC with the coverage of 25 or $50 \%$, the $1 \%$ prevalence target would be reached within 4 or 3 annual treatment rounds respectively in the 'worst-case' scenario, that is when the threshold of high-intensity infections among PSAC is 5 worms.

In Figure 4, we show the number of high-intensity infection case years averted, depending on the PSAC coverage in the MDA and the high-intensity infection threshold among PSAC. The case years averted for different MDA strategies vary the most for the lowest threshold of 5 worms. By including PSAC in the annual MDA with $25 \%$ coverage, about 5 years per 100 people are averted in 5 years of treatment. This value doubles if the coverage is increased to $50 \%$. 
medRxiv preprint doi: https://doi.org/10.1101/2020.12.09.20246652; this version posted December 11, 2020. The copyright holder for this preprint (which was not certified by peer review) is the author/funder, who has granted medRxiv a license to display the preprint in

It is made available under a CC-BY-NC-ND 4.0 International license .
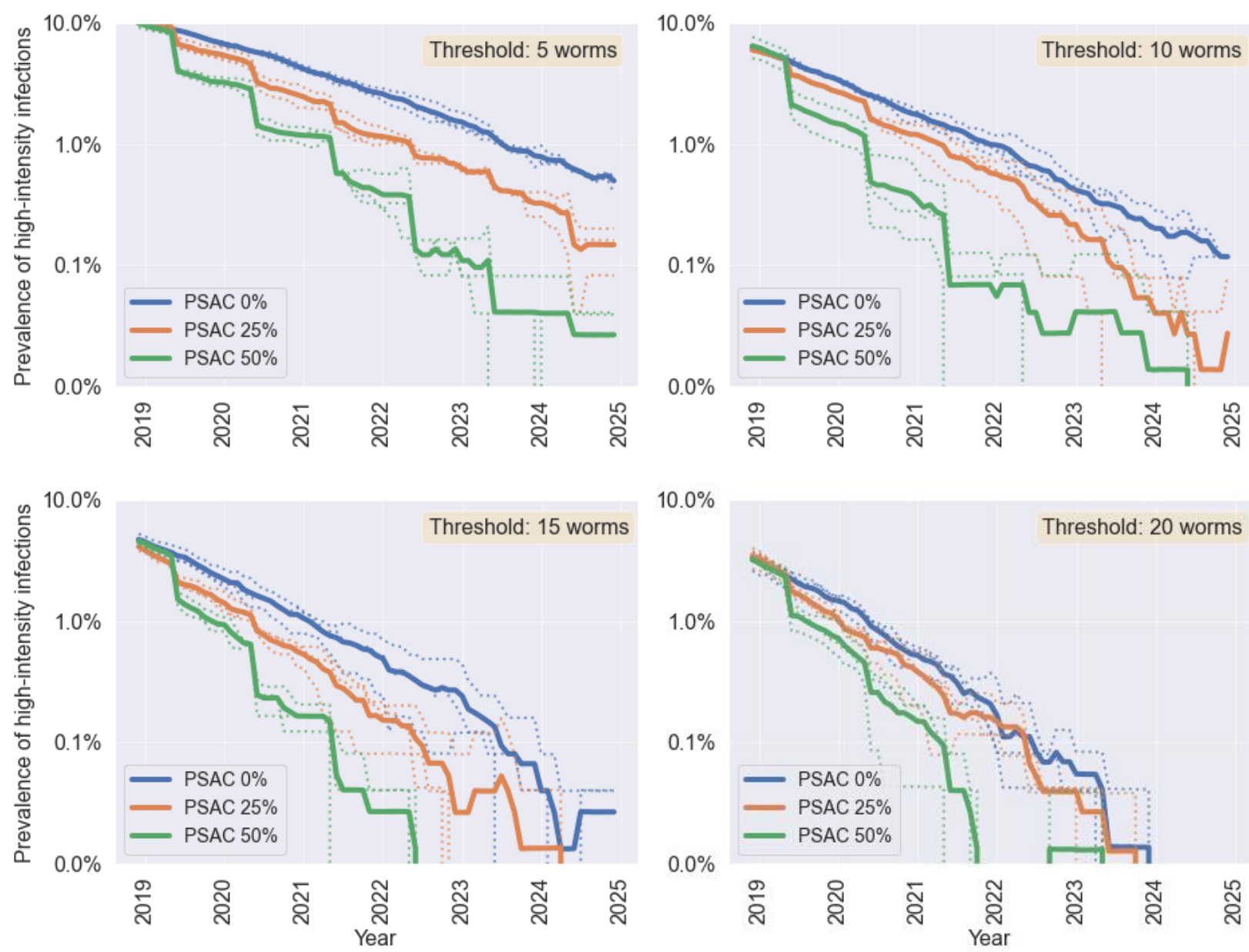

Figure 3 Prevalence of high-intensity infections in PSAC with a worm threshold equal to 5, 10, 15 or 20 worms. Blue line shows scenario of annual MDA with PSAC coverage of 0\%, magenta line - coverage $25 \%$, yellow line - coverage $50 \%$.

Table 5 Rounds of annual MDA needed to decrease the prevalence of high-intensity infections among PSAC below $1 \%$, depending on the threshold of the high-intensity infection.

\begin{tabular}{|l|l|l|l|}
\hline Number of worms / PSAC coverage & PSAC 0\% & PSAC 25\% & PSAC 50\% \\
\hline 5 worms & 5 & 4 & 3 \\
\hline 10 worms & 3 & 2 & 2 \\
\hline 15 worms & 2 & 2 & 1 \\
\hline 20 worms & 2 & 1 & 1 \\
\hline
\end{tabular}


medRxiv preprint doi: https://doi.org/10.1101/2020.12.09.20246652; this version posted December 11,2020 . The copyright holder for this preprint (which was not certified by peer review) is the author/funder, who has granted medRxiv a license to display the preprint in It is made available under a CC-BY-NC-ND 4.0 International license .

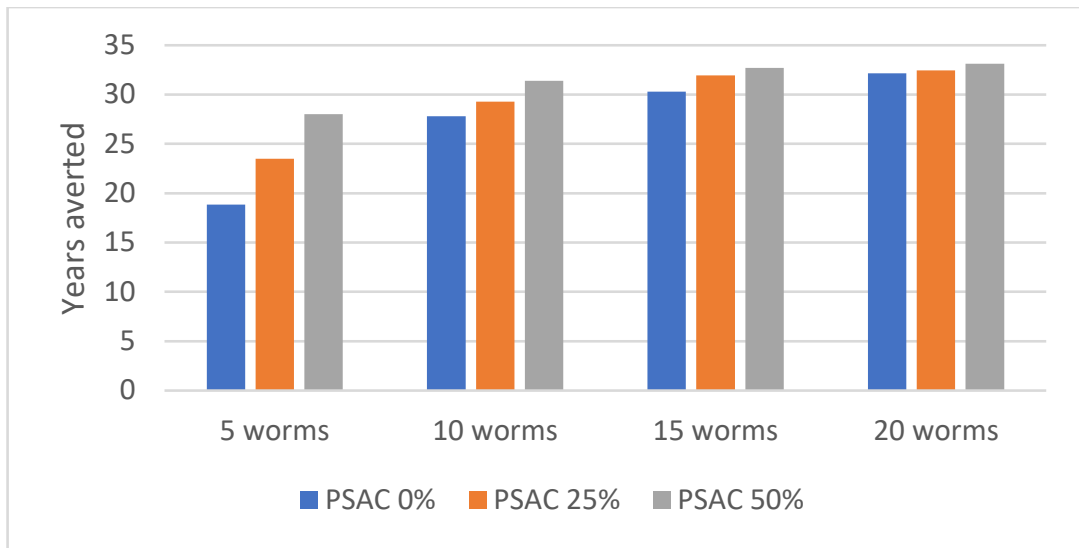

Figure 4 High-intensity infection years averted among PSAC in 5 years of MDA, per 100 children.

\section{Discussion}

We showed that expanding the coverage of MDA to include PSAC can lead to a accelerated decrease in the high-intensity infections in SAC compared to the current strategy. By increasing the PSAC coverage to 25 or $50 \%$ or increasing the frequency of MDA to twice per year without including PSAC, the WHO goal of elimination of urogenital schistosomiasis in the highest burden districts of Malawi can be achieved within only 2 additional rounds of MDA.

The sensitivity analysis, focusing on the high-intensity infections among PSAC, indicated the importance of treating the PSAC in mass drug administration, especially if we consider the 'worst-case' scenario of 5-worms threshold of high-intensity infection in PSAC. Looking at the high-intensity infection case years averted (Figure 4), the impact of including PSAC in the annual MDA programmes is greatest for the worst-case scenario of the high-intensity threshold of 5-worms. Up to 28 high-intensity infection years per 100 children can be averted within 5 years if the coverage of PSAC is increased, in comparison to 18 years if the current strategy is continued.

Including PSAC in the mass drug administration can have a major impact on controlling morbidity due to urogenital infections, not only among PSAC but other age groups as well. One of the biggest risks of chronic infections in PSAC is that they might lead to severe and permanent symptoms later in life. For example, prolonged schistosomiasis infections may lead to developing serious conditions such as infertility, bladder cancer, kidney failure or inflammation of internal organs $(1,5,25,26)$. Moreover, studies have suggested that prenatal and infant exposure to schistosomiasis and other STH might be correlated to a reduction in the efficacy of childhood disease vaccinations (8). Schistosomiasis infections in childhood have also been found to impair growth and reduce learning abilities, causing long-term and irreversible implications in terms of quality of life in adulthood $(1,27-30)$. Taking all this into account, the benefits of treating the pre-school aged children, while difficult to measure, could be immense.

Although children under 5 years old can be administered praziquantel upon the positive diagnosis of the infection by the laboratory test, studies suggest this does not happen regularly (27). The probable reason for that is the poor understanding of the symptoms of schistosomiasis in young children, which are often nonspecific (malnutrition, anaemia, microhaematuria) and easy to mistake for other diseases of poverty or for malaria. This makes the infections extremely difficult to recognise in the early years of the child's life. Moreover, Bustinduy et al. suggest that the common preconception is that the younger children will be treated with praziquantel later in their life, during a school-based MDA campaign, by which time it might already be too late to reverse the damage (27).

Studies conducted in Malawi revealed that schistosomiasis is a common problem in PSAC in rural areas $(31,32)$. Poole et al. examined mothers and their pre-school aged children in 12 villages in the Chikwawa district and showed that around $25 \%$ of children had haematuria or albuminuria. The children had regular and extensive 
medRxiv preprint doi: https://doi.org/10.1101/2020.12.09.20246652; this version posted December 11,2020 . The copyright holder for this preprint (which was not certified by peer review) is the author/funder, who has granted medRxiv a license to display the preprint in It is made available under a CC-BY-NC-ND 4.0 International license .

contact with the infested water, as they often accompanied mothers in the water during daily activities such as washing clothes (31).

The Global Burden of Disease study from 2017 (33) revealed that dietary iron deficiency was the number one cause for most disability in Malawi, having overtaken HIV/AIDS and increased by $34.5 \%$ since 2016. Additionally, in 2017 malnutrition was the prevailing risk factor driving the most death and disability combined. As urogenital schistosomiasis is contributing to both malnutrition and iron deficiency, the paediatric formulation of praziquantel and preventive chemotherapy for the pre-school aged children has the potential of decreasing those two risk factors and consequently reducing the disability levels in Malawi.

Although the control and elimination targets defined by WHO refer only to the high-intensity infections, two things are worth noting. Firstly, the infections are likely to be more pathogenic in the PSAC and infants (9), therefore the same threshold of high-intensity should be used with caution. Secondly, light infections should not be overlooked: their implications are not well understood, and even with a small worm burden the eggs can cause inflammation of the internal tissues $(34,35)$.

The full life cycle of schistosomiasis infection is complex and requires modelling the dynamics of the schistosomes' various life stages, including the dynamics of the snail populations. In many existing models of schistosomiasis infection, including the model presented here, simplifications are introduced, based on the fact that the lifespans of the adult worms are orders of magnitude longer than the preceding life stages (36). In the model described here, we adopted the main assumptions from the Anderson et al. schistosomiasis model (13) and its stochastic version (37), however certain limitations have to be addressed.

Firstly, the model does not explicitly include the probability of adult schistosomes mating, which is important in the low-prevalence districts. Probability of mating is one of the vital issues that drive the population of schistosomes extinct in the areas with low schistosome densities. Because we disregard this characteristic, our model may be overestimating the worms' density in the low-burden districts, however in this study we focused on the high-risk districts, in which the probability of mating is relatively high.

Some people have elevated risks of acquiring schistosomiasis infection. This is caused by a variety of biological, environmental and behavioural factors, such as profession or personal hygiene $(38,39)$. In our models, we allocate those risks and predispositions randomly, which might lead to the underestimation of the worm burden in groups with elevated risks. We still include the tendency of children to spend more time in contact with the water by using age-dependent exposure rates to estimate the risk of acquiring new infection, as well as their increased input of the infectious material to the environment. The proximity to the infested water reservoir is also covered to some extent through using observational data from Malawi to estimate the initial prevalence in each of the districts separately and further assuming no mixing of individuals between the districts. Because of this, we preserve the higher risks of infections in high-prevalence districts, which might be caused by a larger density of water reservoirs, rural areas and poverty $(8,40)$.

To estimate the baseline prevalence, we calculated the average prevalence of S.haematobium infections within each district of Malawi using data often collected from a single school or village. However, schistosomiasis is a highly localised disease dependent on the proximity of the water reservoir with infected snails. As a consequence, prevalence within a district can be highly heterogeneous $(25,41,42)$.

\section{Conclusions}

Our analysis suggests that including pre-school aged children (PSAC) in the MDA campaigns can reduce the time needed to achieve the WHO elimination target in the highest-prevalence districts in Malawi, reaching it one year sooner than with the current strategy. Furthermore, we showed that including the PSAC in the preventive chemotherapy programmes can significantly reduce the number of the high-intensity infection case years for PSAC if their threshold is lower than currently set by WHO guidelines. Although difficult to know with the current knowledge, this might lead to a substantial decrease in the severe morbidities in adult life, such as bladder cancer, infertility or kidney failure, as well as better overall health and development of the children living in the 
medRxiv preprint doi: https://doi.org/10.1101/2020.12.09.20246652; this version posted December $11,2020$. The copyright holder for this preprint (which was not certified by peer review) is the author/funder, who has granted medRxiv a license to display the preprint in It is made available under a CC-BY-NC-ND 4.0 International license .

endemic areas. The uncertainties around the high-intensity infections among PSAC highlight the need for more research in the area of the schistosomiasis morbidities and their complications in PSAC.

\section{Declarations}

Ethics approval and consent to participate

Not applicable.

\section{Consent for publication}

Not applicable.

\section{Availability of data and materials}

All data generated or analysed during this study are included in this published article or the referenced materials. The MDA coverage per year and age group as used in the model is included in the Supplementary Information.

\section{Competing interests}

The authors declare that they have no competing interests.

\section{Funding}

$\mathrm{IH}, \mathrm{TM}$ and TBH acknowledge funding from the MRC Centre for Global Infectious Disease Analysis (reference MR/R015600/1), jointly funded by the UK Medical Research Council (MRC) and the UK Foreign, Commonwealth \& Development Office (FCDO), under the MRC/FCDO Concordat agreement and is also part of the EDCTP2 programme supported by the European Union. TM and TBH were also funded by the Thanzi la Onse grant (RCUK MR/P028004/1).

\section{Authors' contributions}

Model design and manuscript writing: IH, TM, TBH. Model implementation and simulations: IH. Study design and critical review of the manuscript: all authors.

\section{Acknowledgments}

The authors would like to thank other people involved in the design and implementation of the Thanzi la Onse epidemiological model, including Prof. Andrew Phillips, Dr Timothy Colbourn and Dr Asif Tamuri. The authors would also like to thank Dr James Truscott, Dr Klodeta Kura and Dr Robert Hardwick for advice on the transmission model and Dr Hugo Turner for the advice on the current schistosomiasis treatment strategies worldwide.

\section{Abbreviations}

MDA - mass drug administration, PSAC - pre-school aged children, SAC - school aged children, STH - soiltransmitted helminths, TLO - Thanzi la Onse, WB - worm burden, WHO - World Health Organisation

\section{References}

1. Olveda DU, Li Y, Olveda RM, Lam AK, Chau TNP, Harn DA, et al. Bilharzia: Pathology, Diagnosis, Management and Control. Trop Med Surg . 2013 Aug 20;1(4). https://doi.org/10.4172/23299088.1000135

2. McManus DP, Dunne DW, Sacko M, Utzinger J, Vennervald BJ, Zhou X-N. Schistosomiasis. Nat Rev Dis Prim . 2018 Dec 9;4(1):13. https://doi.org/10.1038/s41572-018-0013-8

3. Vos T, Flaxman AD, Lopez AD, Murray CJ. Years lived with disability (YLDs) for 1160 sequelae of 289 diseases and injuries 1990-2010: a systematic analysis for the Global Burden of Disease Study 2010. Lancet . 2012 Dec 15;380(9859):2163-96. https://doi.org/10.1016/S0140-6736(12)61729-2 
medRxiv preprint doi: https://doi.org/10.1101/2020.12.09.20246652; this version posted December 11,2020 . The copyright holder for this preprint (which was not certified by peer review) is the author/funder, who has granted medRxiv a license to display the preprint in

It is made available under a CC-BY-NC-ND 4.0 International license.

4. Mtethiwa AHN, Nkwengulila G, Bakuza J, Sikawa D, Kazembe A. Extent of morbidity associated with schistosomiasis infection in Malawi: A review paper. Infect Dis Poverty. 2015;4(1):1-8.

https://doi.org/10.1186/s40249-015-0053-1

5. Mosunjac M., Tadros T, Beach R, Majmudar B. Cervical schistosomiasis, human papilloma virus (HPV), and human immunodeficiency virus (HIV): a dangerous coexistence or coincidence? Gynecol Oncol . 2003 Jul 1;90(1):211-4. https://doi.org/10.1016/S0090-8258(03)00191-4

6. Ndeffo Mbah ML, Poolman EM, Drain PK, Coffee MP, van der Werf MJ, Galvani AP. HIV and Schistosoma haematobium prevalences correlate in sub-Saharan Africa. Trop Med Int Heal . 2013 Oct 1;18(10):1174-9. doi: 10.1111/tmi.12165

7. Kjetland EF, Ndhlovu PD, Gomo E, Mduluza T, Midzi N, Gwanzura L, et al. Association between genital schistosomiasis and HIV in rural Zimbabwean women. AIDS . 2006 Feb;20(4):593-600. DOI: 10.1097/01.aids.0000210614.45212.0a

8. Osakunor DNM, Woolhouse MEJ, Mutapi F. Paediatric schistosomiasis: What we know and what we need to know. PLoS Negl Trop Dis . 2018;12(2):e0006144.

https://doi.org/10.1371/journal.pntd.0006144

9. Turner HC, Truscott JE, Bettis AA, Farrell SH, Deol AK, Whitton JM, et al. Evaluating the variation in the projected benefit of community-wide mass treatment for schistosomiasis: Implications for future economic evaluations. Parasit Vectors . 2017 Dec 28;10(1):213. https://doi.org/10.1186/s13071-0172141-5

10. World Health Organization. Schistosomiasis: progress report 2001 - 2011, strategic plan 2012 - 2020. World Health Organization; 2013. 74 p. https://apps.who.int/iris/handle/10665/78074

11. WHO. Report of a meeting to review the results of studies on the treatment of schistosomiasis in preschool-age children . Geneva, Switzerland; 2010. https://apps.who.int/iris/bitstream/handle/10665/44639/9789241501880_eng.pdf?sequence=1

12. Pediatric Praziquantel Consortium. http://www.pediatricpraziquantelconsortium.org/schistosomiasis

13. Anderson R, Turner H, Farrell S, Yang J, Truscott $\mathrm{J}$. What is required in terms of mass drug administration to interrupt the transmission of schistosome parasites in regions of endemic infection? Parasit Vectors . 2015 Dec 22;8(1):553. https://doi.org/10.1186/s13071-015-1157-y

14. Kura K, Truscott JE, Toor J, Anderson RM. Modelling the impact of a Schistosoma mansoni vaccine and mass drug administration to achieve morbidity control and transmission elimination. PLoS Negl Trop Dis . 2019;13(6):e0007349. DOI: 10.1371/journal.pntd.0007349 6

15. Deol AK, Fleming FM, Calvo-Urbano B, Walker M, Bucumi V, Gnandou I, et al. Schistosomiasis Assessing Progress toward the 2020 and 2025 Global Goals. N Engl J Med . 2019 Dec 26;381(26):2519-28. DOI: 10.1056/NEJMoa1812165

16. Mishima N, Jemu SK, Kuroda T, Tabuchi K, Darcy AW, Shimono T, et al. Hematobium schistosomiasis control for health management of labor force generation at Nkhotakota and Lilongwe in the Republic of Malawi-assumed to be related to occupational risk. Trop Med Health . 2019 Dec 2;47(1):28. https://doi.org/10.1186/s41182-019-0155-8

17. Cheever AW, Kamel IA, Elwi AM, Mosimann JE, Danner R. Schistosoma mansoni and S. haematobium infections in Egypt. II. Quantitative parasitological findings at necropsy. Am J Trop Med Hyg. 1977;26(4):702-16. DOI: 10.4269/ajtmh.1977.26.702

18. United Nations Department of Economic and Social Affairs. World Population Prospects 2019 . 2019. https://population.un.org/wpp/Download/Standard/Population/

19. National Statistical Office. 2019 Malawi Population and House Census Main Report. National Statistical Office.

http://www.nsomalawi.mw/index.php?option=com_content\&view=article\&id=226\&ltemid=

20. Truscott JE, Gurarie D, Alsallaq R, Toor J, Yoon N, Farrell SH, et al. A comparison of two mathematical models of the impact of mass drug administration on the transmission and control of schistosomiasis. Epidemics . 2017 Mar 1;18:29-37. https://doi.org/10.1016/j.epidem.2017.02.003

21. Anderson RM, May RM. Infectious diseases of humans. Oxford University Press, USA; 1992.

22. Anderson RM, Turner HC, Farrell SH, Truscott JE. Studies of the Transmission Dynamics, Mathematical Model Development and the Control of Schistosome Parasites by Mass Drug 
medRxiv preprint doi: https://doi.org/10.1101/2020.12.09.20246652; this version posted December $11,2020$. The copyright holder for this preprint (which was not certified by peer review) is the author/funder, who has granted medRxiv a license to display the preprint in It is made available under a CC-BY-NC-ND 4.0 International license .

Administration in Human Communities. Adv Parasitol . 2016 Jan 1;94:199-246.

https://doi.org/10.1016/bs.apar.2016.06.003

23. Truscott JE, Ower AK, Werkman M, Halliday K, Oswald WE, Gichuki PM, et al. Heterogeneity in transmission parameters of hookworm infection within the baseline data from the TUMIKIA study in Kenya. Parasites and Vectors. 2019 Sep 16;12(1). https://doi.org/10.1186/s13071-019-3686-2

24. WHO. ESPEN - Expanded Special Project for Elimination Of Neglected Tropical Diseases. http://espen.afro.who.int/countries/malawi

25. Gryseels B, Polman K, Clerinx J, Kestens L. Human schistosomiasis. Lancet . 2006 Sep 23;368(9541):1106-18. https://doi.org/10.1016/S0140-6736(06)69440-3

26. Vennervald BJ, Dunne DW. Morbidity in schistosomiasis: An update. Curr Opin Infect Dis. 2004;17(5):439-47. DOI: 10.1097/00001432-200410000-00009

27. Bustinduy AL, Friedman JF, Kjetland EF, Ezeamama AE, Kabatereine NB, Stothard JR, et al. Expanding Praziquantel (PZQ) Access beyond Mass Drug Administration Programs: Paving a Way Forward for a Pediatric PZQ Formulation for Schistosomiasis. PLoS Negl Trop Dis. 2016 Sep 22;10(9). doi: 10.1371/journal.pntd.0004946

28. King CH, Dickman K, Tisch DJ. Reassessment of the cost of chronic helmintic infection: a metaanalysis of disability-related outcomes in endemic schistosomiasis. Lancet . $2005 \mathrm{Apr}$ 30;365(9470):1561-9. https://doi.org/10.1016/S0140-6736(05)66457-4

29. Phiri KS, Calis JCJ, Faragher B, Nkhoma E, Ng'oma K, Mangochi B, et al. Long Term Outcome of Severe Anaemia in Malawian Children. von Elm E, editor. PLoS One . 2008 Aug 6;3(8):e2903. https://doi.org/10.1371/journal.pone.0002903

30. Stothard JR, Sousa-Figueiredo JC, Betson M, Bustinduy A, Reinhard-Rupp J. Schistosomiasis in African infants and preschool children: Let them now be treated! Vol. 29, Trends in Parasitology. Elsevier Current Trends; 2013. p. 197-205. doi: 10.1016/j.pt.2013.02.001

31. Poole H, Terlouw DJ, Naunje A, Mzembe K, Stanton M, Betson M, et al. Schistosomiasis in preschool-age children and their mothers in Chikhwawa district, Malawi with notes on characterization of schistosomes and snails. Parasites and Vectors. 2014 Apr 1;7(1):153. https://doi.org/10.1186/17563305-7-153

32. Pullanikkatil D, Mubako S, Phalira W, Chiotha S, Luhanga M. Schistosomiasis prevalence in Zomba, Southern Malawi. African Geogr Rev . 2014 Jan 2;33(1):36-51.

https://doi.org/10.1080/19376812.2013.861758

33. IHME. Global Burden of Disease 2017. http://www.healthdata.org/malawi

34. King CH. It's Time to Dispel the Myth of "Asymptomatic" Schistosomiasis. McGarvey ST, editor. PLoS Negl Trop Dis . 2015 Feb 19;9(2):e0003504. https://doi.org/10.1371/journal.pntd.0003504

35. King $\mathrm{CH}$, Dangerfield-Cha M. The unacknowledged impact of chronic schistosomiasis . Vol. 4, Chronic Illness. Sage PublicationsSage UK: London, England; 2008, p. 65-79. https://doi.org/10.1177/1742395307084407

36. Anderson RM, May RM. Helminth Infections of Humans: Mathematical Models, Population Dynamics, and Control. Adv Parasitol . 1985 Jan 1;24:1-101. https://doi.org/10.1016/S0065-308X(08)60561-8

37. Farrell SH, Truscott JE, Anderson RM. The importance of patient compliance in repeated rounds of mass drug administration (MDA) for the elimination of intestinal helminth transmission. Parasit Vectors . 2017 Dec 12; 10(1):291. https://doi.org/10.1186/s13071-017-2206-5

38. Banhela N, Taylor M, Gift Zulu S, Sund Strabo L, Floerecke Kjetland E, Gunnar Gundersen S. Environmental factors influencing the distribution and prevalence of Schistosoma haematobium in school attenders of ILembe and uThungulu Health Districts, KwaZulu-Natal Province, South Africa . South African J Infect Dis . 2017;32(4):132-7. http://doi.org/10.1080/23120053.2017.1335974

39. Knopp S, Person B, Ame SM, Ali SM, Hattendorf J, Juma S, et al. Evaluation of integrated interventions layered on mass drug administration for urogenital schistosomiasis elimination: a clusterrandomised trial. Lancet Glob Heal. 2019;7(8):e1118-29. https://doi.org/10.1016/S2214109X(19)30189-5

40. Moyo VB, Changadeya W, Chiotha S, Sikawa D. Urinary schistosomiasis among preschool children in Malengachanzi, Nkhotakota District, Malawi: Prevalence and risk factors. Malawi Med J . 
medRxiv preprint doi: https://doi.org/10.1101/2020.12.09.20246652; this version posted December 11,2020 . The copyright holder for this preprint (which was not certified by peer review) is the author/funder, who has granted medRxiv a license to display the preprint in It is made available under a CC-BY-NC-ND 4.0 International license .

2016;28(1):10-4. DOI: 10.4314/mmj.v28i1.3

41. Bowie C, Purcell B, Shaba B, Makaula P, Perez M. A national survey of the prevalence of schistosomiasis and soil transmitted helminths in Malawi. BMC Infect Dis . 2004 Nov 16;4:49. DOI: 10.1186/1471-2334-4-49

42. Makaula P, Sadalaki JR, Muula AS, Kayuni S, Jemu S, Bloch P. Schistosomiasis in Malawi: A systematic review. Parasites and Vectors . 2014;7(1). 10.1186/s13071-014-0570-y

\section{Supplementary Information: "The potential impact of including pre-school aged children in the praziquantel mass-drug administration programmes on the S.haematobium infections in Malawi: a modelling study"}

\section{Additional file 1 \\ Assignment of the new infections \\ The transmission model is adapted from earlier work detailed in $(20,21,23,37)$.}

The main idea behind the schistosomiasis model developed for this project is that every individual has a 'worm burden' (WB) which is tracked, and an underlying propensity to become infected, termed the 'harbouring rate'. At birth, individuals have a zero WB and a harbouring rate is drawn from a gamma distribution.

At any particular time, all individuals with a positive worm burden (WB) contribute to the total worm reservoir, from which people acquire new worms with a rate dependent on their age and harbouring rate. The full lifecycle of the schistosomes is simplified and subsumed into the district-dependent parameter R0. Persons can be infected multiple times, which leads to increases in their WB. High-intensity infections are classed as those in persons where the WB exceeds a defined threshold. The worms can be killed with praziquantel, upon administration of which the worm burden decreases.

New infections are assigned independently in every district. Assignment of new infections happens in steps described below.

\section{Calculating the size of the reservoir}

Every person contributes to the total reservoir of infectious material. We do not model the reservoir explicitly by the number of schistosome eggs, instead the reservoir will indirectly model the force of infection.

At each moment, the reservoir is modelled on a district level, by summing all individuals' contribution to the total worm reservoir, that is the worm burden per person multiplied by the age-dependent exposure rate. The exposure rate allows to accommodate for the increased input of the eggs to the environment by the people who spend more time in contact with water, and who are at the same time more exposed (the value of exposure rate depends only on the age of the individual). This value is then multiplied by $R_{0}$.

This is described by the following equation:

$$
L_{\text {district }}=R_{0_{\text {district }}} * \frac{1}{\mid \text { Pop }_{\text {district }} \mid} * \sum_{i \in \text { Pop }_{\text {district }}} \beta_{i} * W B_{i}
$$

Where:

Ldistrict $=$ measure of the number of worms per district combined with the average number of infections arising from each worm,

$\mathrm{R}_{0}$ district $=$ Basic reproduction number in the district,

Popdistrict $=$ the whole population of individuals in the district,

$\beta_{\mathrm{i}}=$ exposure rate of individual $i$,

$W B_{i}=$ worm burden of individual $i$. 
medRxiv preprint doi: https://doi.org/10.1101/2020.12.09.20246652; this version posted December 11,2020 . The copyright holder for this preprint (which was not certified by peer review) is the author/funder, who has granted medRxiv a license to display the preprint in It is made available under a CC-BY-NC-ND 4.0 International license .

(suppressing time dimension from the subscripts)

2. Generating numbers of newly harboured worms

For each individual, a number of newly harboured worms is randomly sampled from a Poisson distribution, accounting for the mean worm burden in the district, the harbouring rate of the individual, and their exposure rate, as per the equation below:

Where:

$$
\text { NewWorms } \text { i,age,district } \sim \operatorname{Poiss}\left(h r_{i} * \beta_{\text {age }} * L_{\text {district }}\right)
$$

NewWormsi, age, district $=$ Number of new worms acquired by individual $i$ of age group age and living in district district,

Poiss ()$=$ random variable drawn from a Poisson distribution,

$\mathrm{hr}_{\mathrm{i}}=$ harbouring rate of individual $\mathrm{i}$,

$\beta_{\text {age }}=$ exposure rate of age group age,

$\mathrm{L}_{\text {district }}=$ mean worm burden in district, as per equation (1).

3. Increasing the worm burden

We say that a new worm has been successfully harboured if the cercariae managed to penetrate the skin, mature into an adult worm and establish itself in the human host organism. This is a densitydependent process, which can be expressed in terms of a probability of successful establishment of the new worms in the host carrying $n$-worms, as given in the equation below:

$$
\operatorname{Prob}(\text { establishment } \mid W B=n)=\exp (-f e c * n)(3)
$$

where $f e c$ is a constant fecundity parameter of the worms, set to 0.005 (20).

For every person who is assigned a positive number of new worms, a random variable is generated from Bernoulli( $p$ ) with probability $p$ as given in equation (3). The value of this variable, 0 or 1 , determines whether the establishment of the new worms succeeded, and hence the worm burden increases, or failed, in which case the worm burden does not change.

The increase in the worm burden for an individual $i$ of age age with current $\mathrm{WB}=n$ is effectively drawn from Poiss $\left(h r_{i} * \beta_{\text {age }} * L_{\text {district }}\right) *$ Bernoulli $(-f e c * n)$.

4. For people whose worm burden increases due to the successful establishment of new worms, the increment happens only after a period of the worms' maturation, which is taken to be a period lasting 25-30 days (21).

All parameters are fixed throughout the simulation. Their values are given in Error! Reference source not found. and 2 in the main manuscript text.

\section{Additional file 2}

\section{Calibrating the parameters}

Parameters $k$ and $R_{0}$ were calibrated to the given prevalence of every district, as per the equations below, following the methodology from $(21,23)$.

Parameters $\mathrm{k}$ (clumping parameter), $\mathrm{P}$ (prevalence), MWB and $\mathrm{R}_{0}$ are all district dependent, but for clarity, we drop the district-index here. Parameter $y$ was equal to 0.005 (20).

$$
\begin{gathered}
k(b, P)=b * P \quad(4 \mathrm{a}) \\
M W B(k, P)=k\left[(1-P)^{-1 / k}-1\right](4 \mathrm{~b}) \\
R_{0}=\frac{1}{f} \quad(4 \mathrm{c}) \\
f(M W B, k)=\left[1+(1-z) \frac{M}{k}\right]^{-k-1} * \varphi(m, k)
\end{gathered}
$$


medRxiv preprint doi: https://doi.org/10.1101/2020.12.09.20246652; this version posted December 11,2020 . The copyright holder for this preprint (which was not certified by peer review) is the author/funder, who has granted medRxiv a license to display the preprint in

It is made available under a CC-BY-NC-ND 4.0 International license.

$$
\begin{array}{r}
\varphi(m, k)=1-\left(\frac{1-\sigma}{2 \pi}\right)^{1+k} * \int_{0}^{2 \pi} \frac{1-\cos \theta}{(1-\sigma \cos \theta)^{1+k}} d \theta \\
\sigma=\frac{M W B}{M W B+k}, \quad z=e^{-\gamma}
\end{array}
$$

For the soil-transmitted helminths (STH), parameter $\mathrm{b}$ in the equation $4 \mathrm{a}$ is estimated to be approximately 0.5 (23). For schistosomiasis, this parameter should be less than for the STH, because of the differences in the reproduction processes between those groups of parasites. To find an appropriate value for the parameter $b$, we performed grid search in the space $b \in[0.2,0.3,0.4,0.5]$. Parameter value $b=0.4$ was chosen as a parameter that minimised the difference between the observed data and model outputs.

Applying equations $4 a-4 e$ to the baseline prevalence, we obtain the calibrated parameters $k$ and $R_{0}$ for every district of interest. The results of these calculations are shown in Table 3 in the manuscript text.

\section{Additional file 3}

Mass-drug administration coverage data

\begin{tabular}{|l|l|l|l|l|l|}
\hline District & Age group & 2015 & 2016 & 2017 & 2018 \\
\hline \multirow{3}{*}{ Blantyre } & SAC & $78 \%$ & $85 \%$ & $92 \%$ & $87 \%$ \\
\cline { 2 - 6 } & Adults & $0 \%$ & $44 \%$ & $88 \%$ & $88 \%$ \\
\hline \multirow{3}{*}{ Chiradzulu } & SAC & $73 \%$ & $80 \%$ & $87 \%$ & $87 \%$ \\
\cline { 2 - 6 } & Adults & $2 \%$ & $15.5 \%$ & $29 \%$ & $90 \%$ \\
\hline \multirow{3}{*}{ Nkhotakota } & SAC & $48 \%$ & $60.5 \%$ & $73 \%$ & $73 \%$ \\
\cline { 2 - 6 } & Adults & $96 \%$ & $96 \%$ & $96 \%$ & $96 \%$ \\
\cline { 2 - 6 } & Adults & $50 \%$ & $67.5 \%$ & $85 \%$ & $85 \%$ \\
\hline \multirow{3}{*}{ Nsanje } & SAC & $7 \%$ & $22 \%$ & $43 \%$ & $89 \%$ \\
\cline { 2 - 6 } & Adults & $0 \%$ & $79.5 \%$ & $84 \%$ & $90 \%$ \\
\hline & SAC & $92 \%$ & $41 \%$ & $82 \%$ & $88 \%$ \\
\cline { 2 - 6 } & Adults & $4 \%$ & $88 \%$ & $84 \%$ & $86 \%$ \\
\hline
\end{tabular}

\section{Supplementary Information References}

1. Anderson RM, May RM. Infectious diseases of humans. Oxford University Press, USA; 1992.

2. Truscott JE, Gurarie D, Alsallaq R, Toor J, Yoon N, Farrell SH, et al. A comparison of two mathematical models of the impact of mass drug administration on the transmission and control of schistosomiasis. Epidemics. 2017 Mar 1;18:29-37. https://doi.org/10.1016/i.epidem.2017.02.003

3. Truscott JE, Ower AK, Werkman M, Halliday K, Oswald WE, Gichuki PM, et al. Heterogeneity in transmission parameters of hookworm infection within the baseline data from the TUMIKIA study in Kenya. Parasites and Vectors. 2019 Sep 16;12(1). https://doi.org/10.1186/s13071-019-3686-2

4. Farrell SH, Truscott JE, Anderson RM. The importance of patient compliance in repeated rounds of mass drug administration (MDA) for the elimination of intestinal helminth transmission. Parasit Vectors. 2017 Dec 12;10(1):291. https://doi.org/10.1186/s13071-017-2206-5 